\title{
Ultrasensitive Biosensor for Detection of Organophosphorus Pesticides Based on a Macrocycle Complex/Carbon Nanotubes Composite and 1-Methyl-3-octylimidazolium Tetrafluoroborate as Binder Compound
}

\author{
Neuma das Mercês Pereira, ${ }^{11}$ Fernando Mota de Oliveira, ${ }^{* 1}$ Nara Rúbia Pereira,*2 \\ Rodrigo Moreira VerLY, ${ }^{* 1}$ Dênio Emanuel Pires Souto, ${ }^{* 3}$ Lauro Tatsuo Kubota, ${ }^{* 3}$ \\ Auro Atsushi TanaKa, ${ }^{* 4}$ Flavio Santos Damos, ${ }^{* 4}$ and Rita de Cássia Silva Luz ${ }^{* 4 \dagger}$ \\ *1 Departamento de Química, UFVJM, 39100-000, Diamantina, MG, Brazil \\ *2 Instituto de Ciências Exatas e Biológicas, UFOP, 35400-000, Ouro Preto, MG, Brazil \\ *3 Instituto de Química, UNICAMP, P. O. Box 6154, 13083-970, Campinas, SP, Brazil \\ *4 Departamento de Química, UFMA, 65080-805, São Luís, MA, Brasil
}

\begin{abstract}
This work describes the highly sensitive detection of organophosphorus pesticides employing the cobalt(II) 4,4,4,4-tetrasulfo-phthalocyanine (CoTSPc) macrocycle complex, carbon nanotubes (CNT), and 1-methyl-3octylimidazolium tetrafluoroborate $\left.\left(\mathrm{OMIM}_{\mathrm{B}} \mathrm{BF}_{4}\right]\right)$. The technique is based on enzyme acetylcholinesterase $(\mathrm{AChE})$ inhibition. The composite was characterized by scanning electron microscopy (SEM), Fourier transform infrared (FT-IR) spectroscopy, and amperometry. The AChE was immobilized on the composite electrode surface by cross-linking with glutaraldehyde and chitosan. The synergistic action of the CoTSPc/CNT/OMIM[BF 4 composite showed excellent electrocatalytic activity, with a low applied potential for the amperometric detection of thiocholine (TCh) at $0.0 \mathrm{~V} v s$. $\mathrm{Ag} / \mathrm{AgCl}$. The calculated catalytic rate constant, $k_{\text {cat }}$, was $3.67 \times 10^{3} \mathrm{~mol}^{-1} \mathrm{~L} \mathrm{~s}^{-1}$. Under the optimum conditions, the inhibition rates of these pesticides were proportional to their concentrations in the ranges of $1.0 \mathrm{pmol} \mathrm{L}^{-1}$ to $1.0 \mathrm{nmol} \mathrm{L}^{-1}$ (fenitrothion), 2.0 pmol L$)^{-1}$ to $8.0 \mathrm{nmol} \mathrm{L}^{-1}$ (dichlorvos), and $16 \mathrm{pmol} \mathrm{L}^{-1}$ to $5.0 \mathrm{nmol} \mathrm{L}^{-1}$ (malathion).
\end{abstract}

Keywords Biosensor, cetylcholinesterase, $\mathrm{CoTsPc}, \mathrm{CNT}, \mathrm{OMIM}\left[\mathrm{BF}_{4}\right]$, OP pesticides

(Received June 22, 2014; Accepted October 31, 2014; Published January 10, 2015)

\section{Introduction}

The term "pesticides" is used to describe a very wide range of substances employed as weed killers, insecticides, fungicides, and other similar agents. Rivers and groundwater may contain traces of pesticides resulting from agricultural use (especially pest control in crops) and non-agricultural use (such as herbicides used for weed control on highways and railways). EU regulations specify maximum concentrations of $0.1 \mu \mathrm{g} \mathrm{L}^{-1}$ (individual pesticides) and $0.5 \mu \mathrm{g} \mathrm{L}^{-1}$ (total pesticides) (EU Directive 2000/60/EC). ${ }^{1}$

Organophosphorus (OP) pesticides comprise a heterogeneous group of compounds that include some of the most toxic chemicals specifically designed for the control of pests, weeds, and plant diseases. Their application remains one of the most effective and accepted means of protecting plants, and has contributed significantly to enhanced agricultural productivity and crop yields. ${ }^{2}$ The toxicity of OP pesticides is due to the ability of these compounds to inhibit the enzyme acetylcholinesterase (AChE) at cholinergic junctions of the

$\dagger$ To whom correspondence should be addressed.

E-mail: rita.luz@ufma.br nervous system. Thiocholine (TCh) is one of the products of acetylthiocholine (ATCh) hydrolysis with enzyme AChE, and its detection can be used to evaluate the activity of AChE, which is a biomarker for the biological effect of certain pesticides (organophosphates and carbamates) that inhibit the activity of AChE in muscle and nerve tissues. ${ }^{3,4}$ Biosensors based on inhibition of the AChE are the most frequently used for the identification and quantification of OP pesticides, due their advantages of simplicity, rapidity, reliability, and low cost. ${ }^{5}$ The oxidation of TCh occurs at a relative high potential $(\sim 700 \mathrm{mV})$ on carbon-based electrodes. ${ }^{6}$ Therefore, the reduction of the working potential can be achieved by using mediators that provide higher selectivity and sensitivity. ${ }^{6-18}$ However, a major disadvantage of most biosensors developed for pesticides is that they do not have sufficient sensitivity to measure sub-nanomolar concentrations, so the search for new devices is very important for the development of highly sensitive systems.

Carbon nanotubes (CNT) are promising materials for sensing applications due to their unique electronic properties that are distinct from that of other carbonaceous materials. The small dimensions, functional surfaces, good conductivity, excellent biocompatibility, modifiable sidewalls, and high reactivity of CNT make them highly suitable for the fabrication of high performance electrochemical sensors. ${ }^{19}$ Ionic liquids (ILs) are a 
group of chemicals that have gained increasing attention as alternative solvents in recent years. ${ }^{20}$ These substances are molten salts whose melting points are close to, or below, room temperature. The good solvating properties, high conductivity, non-volatility, low toxicity, wide electrochemical window (i.e. the electrochemical potential range over which the electrolyte is neither reduced nor oxidized on electrodes), and good electrochemical stability make ILs suitable for many applications. ${ }^{20}$ ILs based on imidazolium cation has been shown to be very promising for electrochemical applications, ${ }^{6}$ however, there are few reports concerning the use of ionic liquids in the development of pesticide biosensors.

Carbon nanotubes can be easily dispersed in ILs, with the high viscosity greatly enhancing the conductivity. This, together with high chemical and electrochemical stability, means that these systems have considerable potential in electrochemical applications. $^{20}$ The synergistic effect of the counterparts is exploited in different type of composites in order to improve the analytical performances of composite modified electrodes. ${ }^{6}$

The gel between CNT and imidazolium ionic liquids act as better materials for improving the electrochemical transfer in electrochemical biosensors. ${ }^{6}$ However, in many cases, electrochemical sensors based on ionic liquids and carbon nanotubes are unable to provide the sensitivity required for the detection of species present at very low concentrations. This problem can be resolved using electron-transfer mediators that, and besides increasing the sensitivity of the system, are able to decrease the overpotential required for oxidation or reduction of the analyte.

Metallic macromolecules, such as phthalocyanines, are particularly attractive for this purpose due to their physical and chemical properties, which include high thermal and chemical stability, non-toxicity, defined redox activity, semiconductivity and catalytic efficiency. ${ }^{21}$ Cobalt phthalocyanine tetrasulfonate (CoTSPc) readily adsorbs on graphite substrates forming very stable layers which show electrocatalytic activity for the redox process of molecules. ${ }^{22}$ The smart integration of carbon nanotubes with metallophthalocyanine complexes and ionic liquids on electrode surfaces has the potential to improve the electrocatalytic response of certain analytes compared to the individual use of these materials, and consequently a higher sensitivity and lower detection limit. In this sense, the present work describes the development of a novel biosensor that is efficient, ultrasensitive, reusable, and stable. The device is based on the enzyme AChE immobilized on a macrocycle complex (tetrasulfonated cobalt phthalocyanine-CoTSPc), multi-walled carbon nanotubes, and the ionic liquid 1-methyl-3octylimidazolium tetrafluoroborate $\left.\left(\mathrm{OMIM}_{\mathrm{B}} \mathrm{BF}_{4}\right]\right)$ used as an agglutination agent. The proposed method is based on the inhibition of enzymatic activity, measured by amperometric detection of $\mathrm{TCh}$ at a CoTSPc/CNT/OMIM[BF 4 composite paste electrode (Fig. S1, Supporting Information). In this sense, the detection of the pesticides is simply based on the determining the difference in enzyme activity in the presence and absence of inhibitor, according to the following equations:

$$
\begin{aligned}
& \text { Acetylthiocholine }(\mathrm{ATCh})+\mathrm{H}_{2} \mathrm{O} \underset{\mathrm{AChE}}{\longrightarrow} \\
& \text { Thiocholine }(\mathrm{TCh})+\text { acetic acid, } \\
& 2 \text { Thiocholine (TCh) }-2 \mathrm{e}^{-} \stackrel{\begin{array}{c}
\text { Anodic } \\
\text { oxidation }
\end{array}}{\underset{\text { dithio-bis-choline }+2 \mathrm{H}^{+} .}{\longrightarrow}}
\end{aligned}
$$

The enzymatic biosensor was successfully employed for the detection of organophosphorus pesticides without any kind of sample pretreatment. To our knowledge, this is the first time that AChE has been immobilized onto a CoTSPc/CNT/ $\mathrm{OMIM}\left[\mathrm{BF}_{4}\right]$ paste electrode for the determination of $\mathrm{OP}$ pesticides at picomolar levels.

\section{Experimental}

\section{Reagents and apparatus}

Multi-walled carbon nanotubes (diameter $7-15 \mathrm{~nm}$, length $0.5-10 \mu \mathrm{m},>90 \%$ purity), AChE (100 $\left.\left.\mathrm{U} \mathrm{mL}^{-1}\right), \mathrm{OMIM}^{\mathrm{B}} \mathrm{BF}_{4}\right]$ (99\% purity), ATCh, TCh, glutaraldehyde (25\%), fenitrothion, dichlorvos, and malathion were purchased from Sigma-Aldrich (St. Louis, MO). CoTSPc was synthesized and purified according to the procedure of Weber and Busch. ${ }^{23}$ Chitosan (95\% deacetylation), phosphate buffer (PBS, $\mathrm{pH} 8.0$ ), and other reagents were of analytical grade.

Scanning electron microscopy (SEM) was performed using a JSM-6510LV instrument. For electronic microscopic analysis, we used carbon ribbon to deposit only the CNT, only CoTsPc complex and the CNT/CoTsPc composite. Fourier-transform infrared (FT-IR) spectra were obtained using a UV-Vis-NIR Cary-5000 spectrometer in the region of $4000-400 \mathrm{~cm}^{-1} .1 \%$ $\mathrm{KBr}$ tablets were prepared for analysis of each material (CNT, CoTsPc complex and the CNT/CoTsPc composite). Electrochemical measurements were performed with an Autolab PGSTAT $128 \mathrm{~N}$ potentiostat/galvanostat (Eco Chemie) coupled to a microcomputer and controlled with NOVA 1.5 software. A three-electrode electrochemical cell was employed for all electrochemical measurements. The electrodes were inserted into a 5-mL beaker, through holes in a Teflon ${ }^{\circledR}$ cover. The working electrode was a Metrohm carbon paste electrode (3.0 mm in diameter) modified with the CoTSPc/CNT/ $\mathrm{OMIM}\left[\mathrm{BF}_{4}\right]$ composite containing $\mathrm{AChE}$ on the surface. The auxiliary and reference electrodes were a platinum wire and $\mathrm{Ag} /$ $\mathrm{AgCl}_{\text {sat }}$ containing $\mathrm{KCl}\left(3 \mathrm{~mol} \mathrm{~L}^{-1}\right)$, respectively. In this study, all of the potentials were reported with respect to this reference electrode.

\section{Preparation of the CoTSPc/CNT/OMIM $\left[\mathrm{BF}_{4}\right]$ composite material}

The adsorption of CoTSPc on the CNT was carried out by mixing $100 \mathrm{mg}$ of CNT with $5 \mathrm{~mL}$ of a $1 \mathrm{mmol} \mathrm{L}^{-1}$ solution of CoTSPc in DMSO, under ultrasonic agitation for $10 \mathrm{~min}$, and then leaving the material to stand for $24 \mathrm{~h}$. The solid was separated using a filter paper, and washed with doubly distilled water. The resultant composite was compact, with high mechanical stability and low electrical resistance, and could be easily renewed. $5 \mu \mathrm{L}$ of the $\mathrm{OMIM}\left[\mathrm{BF}_{4}\right]$ ionic liquid was then added and mixed with the CoTSPc/CNT composite material.

\section{AChE solution preparation and CoTSPc/CNT/OMIM[BF $\left.{ }_{4}\right] /$ AChE biosensor fabrication}

Firstly, $0.02 \mathrm{~g}$ of chitosan were added to $2 \mathrm{~mL}$ of acetic acid $(0.16 \mu \mathrm{mol} \mathrm{L}-1)$, forming a colloid that was stored at $4^{\circ} \mathrm{C}$. Subsequently, a solution of $10 \mu \mathrm{L}$ of AChE liquid $(100 \mathrm{U} / \mathrm{mL}$ protein), $5.0 \mu \mathrm{L}$ of chitosan colloid $(10.0 \%)$, and $5 \mu \mathrm{L}$ of glutaraldehyde $(50 \%)$ were mixed and stored at $4^{\circ} \mathrm{C}$ before use. The chitosan membrane material contains a large number of $-\mathrm{NH}_{2}$ and $\mathrm{OH}$ groups, which help to maintain a high biological activity of immobilized biomolecules. Further advantages of chitosan are its non-toxicity and low cost. Therefore, it is widely used as a carrier material for enzyme immobilization. Chitosan can provide a favorable microenvironment and prolong the storage life of enzymes. ${ }^{12}$ 
The CoTSPc/CNT composite material and OMIM $\left[\mathrm{BF}_{4}\right]$ were mixed and inserted into the end of the working electrode, after which $5 \mu \mathrm{L}$ of the AChE solution was dropped onto the CoTSPc/ $\mathrm{CNT} / \mathrm{OMIM}\left[\mathrm{BF}_{4}\right]$ composite electrode surface. The resulting system, called the CoTSPc/CNT/OMIM $\left[\mathrm{BF}_{4}\right] / \mathrm{AChE}$ biosensor, was left to dry for $3-4 \mathrm{~h}$ at $4^{\circ} \mathrm{C}$, after which the biosensor was inserted in a solution of $0.1 \mathrm{~mol} \mathrm{~L}^{-1}$ phosphate buffer $(\mathrm{pH} \mathrm{8.0)}$ and $50.0 \mathrm{mmol} \mathrm{L}^{-1}$ of ATCh. The solution $\mathrm{pH}$, ATCh concentration, and incubation time were varied in order to identify the optimal immobilization conditions. In this work, at least three replicates were performed for each parameter.

Study of the incubation time of the CoTSPc/CNT/OMIM[BF $\left.{ }_{4}\right] /$ AChE biosensor in the pesticide solution and amperometric pesticides determination

The longer an enzyme is incubated with its substrate, the greater the amount of product that will be formed. To determine the best incubation time of the CoTSPc/CNT/OMIM[BF $\left.{ }_{4}\right] /$ $\mathrm{AChE}$ biosensor, the modified electrode was immersed in $1.0 \mathrm{nmol} \mathrm{L}{ }^{-1}$ pesticide solution for several incubation times (from 2 up to $16 \mathrm{~min}$ ). After each inhibition experiment, the biosensor was rinsed and inserted into the electrochemical cell containing a $5 \mathrm{~mL}$ phosphate buffer solution $\left(0.1 \mathrm{~mol} \mathrm{~L}^{-1}\right.$, $\mathrm{pH}$ 8.0) and $50.0 \mathrm{mmol} \mathrm{L}^{-1}$ ATCh for the amperometric measurements at $0.0 \mathrm{~V}$ (versus $\mathrm{Ag} / \mathrm{AgCl}$ ).

The pesticide detection was carried out with a two-step procedure. The initial response of the biosensor for $50.0 \mathrm{mmol} \mathrm{L}^{-1}$ of ATCh was recorded as $\Delta I_{0}$; then, the biosensor was incubated for $6 \mathrm{~min}$ in $5 \mathrm{~mL}$ of standard solutions of pesticides. After incubation, the biosensor was washed with a phosphate buffer solution and distilled water many times. The biosensor was transferred to a cell containing $5 \mathrm{~mL}$ of phosphate buffer solution $(\mathrm{pH} 8.0)$ and $50 \mathrm{mmol} \mathrm{L}^{-1}$ of ATCh and the amperometric measurement was carried out. The current shift was recorded as $\Delta I_{1}$. The percent of pesticide inhibition $(I, \%)$ was calculated as follows: ${ }^{24}$

$$
I, \%=\frac{\Delta I_{0}-\Delta I_{1}}{\Delta I_{0}} \times 100
$$

where $\Delta I_{0}$ is the ATCh current at the biosensor without inhibition, and $\Delta I_{1}$ is the ATCh current at the biosensor with pesticide inhibition.

Analytical curves were constructed in the concentration range of 0.001 up to $1.0 \mathrm{nmol} \mathrm{L}^{-1}, 0.002$ up to $8.0 \mathrm{nmol} \mathrm{L}^{-1}$ and $0.00 \mathrm{up}$ to $5.0 \mathrm{nmol} \mathrm{L}^{-1}$ for fenitrothion, dichlorvos and malathion, respectively.

\section{Results and Discussion}

\section{Composite characterization}

The characterization of the unmodified CNT, the CoTSPc complex, and the CoTSPc/CNT composite was performed by SEM and FT-IR. SEM micrographs of the CNT, unmodified or with CoTSPc, are shown in Figs. 1(a) and 1(b), respectively. The molecules of the complex were well distributed over the surface of the CNT, without the formation of large aggregates.

FT-IR images of the materials are shown in Fig. 1(c) (unmodified CNT), Fig. 1(d) (CoTSPc complex), and Fig. 1(e) (CoTSPc/CNT composite). For the unmodified CNT, the spectrum showed a band at $3440 \mathrm{~cm}^{-1}$ associated with the axial strain of $\mathrm{H}-\mathrm{H}$ intramolecular bonds. A typical CNT band was observed between 2850 and $3000 \mathrm{~cm}^{-1}$, with a maximum at $2920 \mathrm{~cm}^{-1}$, attributed to $\mathrm{C}-\mathrm{H}$ stretching. ${ }^{25}$ A second band, with a peak at $1625 \mathrm{~cm}^{-1}$, was associated with stretching vibration of
$-\mathrm{C}=\mathrm{C}$ - in the CNT skeleton. ${ }^{26}$ The bands observed in the spectrum obtained for the CoTSPc complex corresponded to vibrations of specific groups found in the molecular structure of the compound. ${ }^{27}$

The spectrum obtained for the CoTSPc/CNT composite confirmed that modification of the CNT by the CoTSPc complex occurred through a process of physical adsorption, since the characteristic bands of compounds observed in Figs. 1(c) and 1(d) were again observed after modification of the CNT, without the appearance of new bands in the spectrum of the composite.

Electrochemical behavior of the CoTSPc/CNT/OMIM[BF $\left.{ }_{4}\right] /$ AChE biosensor and amperometric curves of TCh

The voltammetric characteristics of TCh on the CNT/ OMIM[BF 4 , CoTSPc/CNT/OMIM[BF 4 , and CoTSPc/CNT/ $\mathrm{OMIM}\left[\mathrm{BF}_{4}\right] / \mathrm{AChE}$ materials were investigated by cyclic voltammetry in the potential range of -0.28 to $0.12 \mathrm{~V}$ vs. Ag/ $\mathrm{AgCl}$, in phosphate buffer containing $50.0 \mathrm{mmol} \mathrm{L}^{-1}$ of $\mathrm{TCh}$. The cyclic voltammograms (CV) obtained are shown in Fig. 2. The enzyme was immobilized on the CoTSPc/CNT/OMIM[BF 4 composite by cross-linking with glutaraldehyde and chitosan, an inert protein possessing amine groups $\left(\mathrm{NH}_{2}\right)$ that participate in the cross-linking reaction. ${ }^{28}$

As shown in Fig. 2(a) (curve 1), no peak was observed for $\mathrm{CNT} / \mathrm{OMIM}\left[\mathrm{BF}_{4}\right]$. In curve 2 of Fig. 2(a), a redox couple can be seen, with anodic and cathodic peaks at about 0.0 and $-0.18 \mathrm{~V}$ vs. $\mathrm{Ag} / \mathrm{AgCl}$, respectively. These peaks can be attributed to oxidation and reduction of the metallic cobalt site of the CoTSPc. However, in curve 3 of Fig. 2a, the anodic oxidation peak at $0.0 \mathrm{~V} v s$. $\mathrm{Ag} / \mathrm{AgCl}$ was due to the oxidation of TCh (the hydrolysis product of ATCh) catalyzed by the immobilized AChE and the peak current showed a sharp increase. This potential is about $700 \mathrm{mV}$ vs. $\mathrm{Ag} / \mathrm{AgCl}$ lower than the potential of direct oxidation of TCh on an unmodified carbon paste electrode (inset of Fig. 2a).

The low oxidation overvoltage of TCh and the increase of current at the CoTSPc/CNT/OMIM[BF 4 / $/ \mathrm{AChE}$ biosensor was due to the electrocatalytic activity of the CoTSPc complex, the large working surface area and electrical conductivity of the CNT. Furthermore, the presence of the ionic liquid (OMIM[BF $\left.\left.{ }_{4}\right]\right)$ can accelerate the electron-transfer kinetics of TCh oxidation due to the electrostatic interaction at $\mathrm{pH} 8.0$ (the optimum $\mathrm{pH}$ for AChE) between negatively charged TCh and the imidazolium cation. ${ }^{29}$ The enzymatically formed TCh can be electrochemically oxidized at a low applied potential $(0.0 \mathrm{~V})$. The coupling of the enzymatic oxidation of TCh and the electrochemical reduction of CoTSPc forms a reaction cycle, which results in amplification of the signal. A fast and efficient electroreduction of CoTSPc at the modified electrode makes it possible to recycle the substrate almost quantitatively, which provides the proposed AChE biosensor with an additional advantage in terms of operational stability.

Cyclic voltammograms were also obtained with Nujol oil in replacement of the ionic liquid as binder compound (Fig. 2(b)). In the presence of the substrate (ATCh), the Nujol oil/CNT paste electrode produced no peak in the CV (Fig. 2(b), curve 1), while the CoTSPc/CNT/Nujol oil paste electrode produced a couple redox of the CoTSPc complex (Fig. 2(b), curve 2). The oxidation peak for TCh (Fig. 2(b), curve 3) was very low in comparison to the CV of Fig. 2(a) (curve 3), which confirms the fundamental importance of the ionic liquid for the oxidation process of TCh.

In Fig. 3 the response of CNT/Nujol oil, CNT/OMIM[BF 4 , CoTSPc/CNT/Nujol oil, CoTSPc/CNT/OMIM[BF $\left.{ }_{4}\right]$, CoTSPc/ $\mathrm{CNT} / \mathrm{Nujol}$ oil/AChE, and CoTSPc/CNT/OMIM[BF 4 ]/AChE 

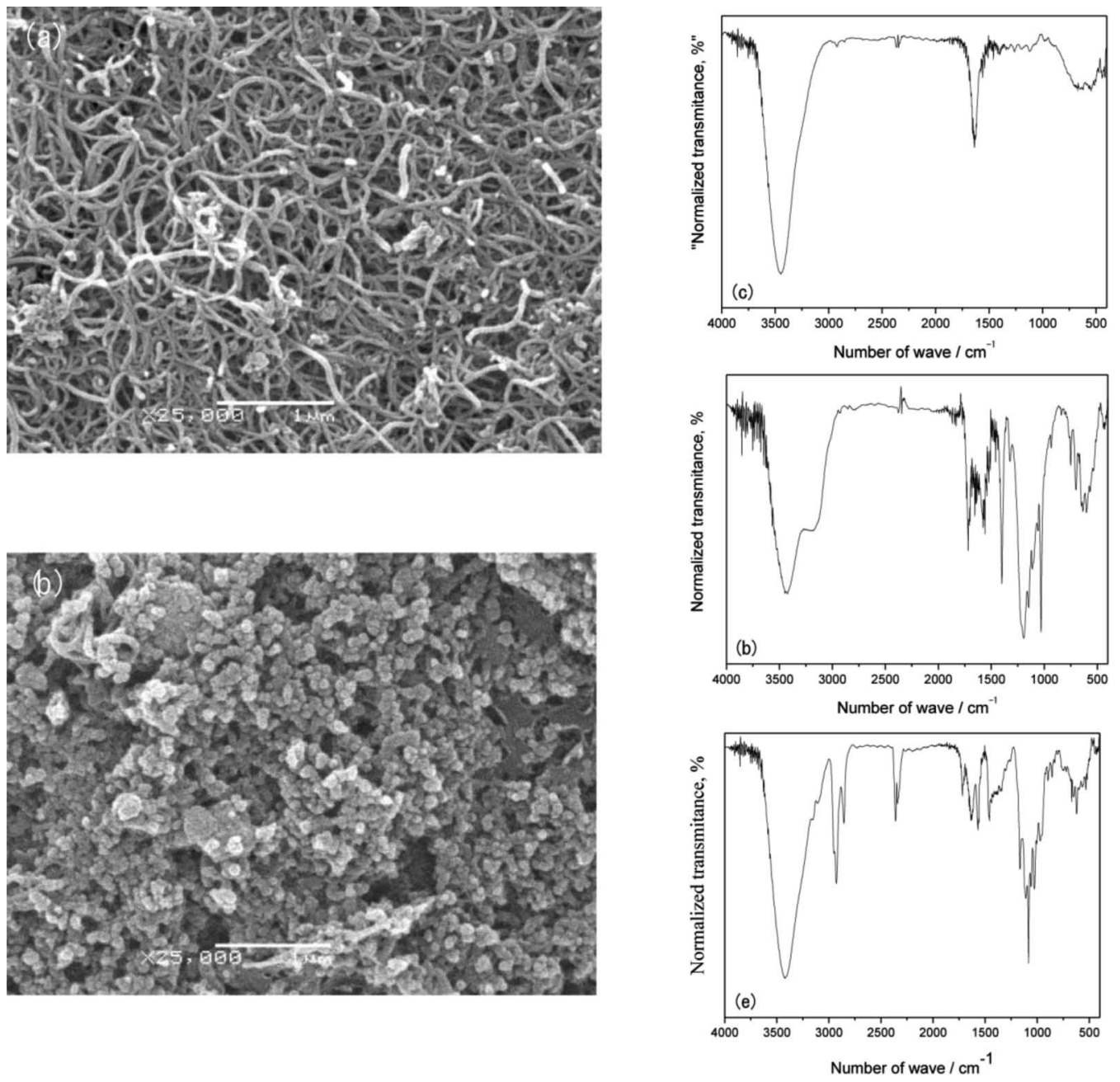

Fig. 1 SEM images of (a) unmodified CNT and (b) CoTSPc/CNT composite, and FT-IR analyses of (c) CNT, (d) the CoTSPc complex, and (e) the CoTSPc/CNT composite.

electrodes at different ATCh concentrations were investigated by amperometry under an applied potential of $0.0 \mathrm{~V} v s . \mathrm{Ag} / \mathrm{AgCl}$. Successive aliquots of 83.0, 95.0, 113.0, 125.0, 138.0 and $150.0 \mu \mathrm{L}$ of ATCh from stock solution of $2.0 \mathrm{~mol} \mathrm{~L}^{-1}$ were added into $5 \mathrm{~mL}$ of $0.1 \mathrm{~mol} \mathrm{~L}^{-1}$ phosphate buffer solution $(\mathrm{pH} \mathrm{8.0)}$ at a time interval of $10 \mathrm{~s}$ after each addition. The applied potential was chosen based on measurements of the catalytic current in the optimized conditions and the highest current verified at an applied potential of $0.0 \mathrm{~V}$ versus $\mathrm{Ag} / \mathrm{AgCl}$.

As shown in Fig. 3 (curves 1 - 4), no electrochemical response was observed for composite materials in the absence of AChE. However, in curves 5 and 6 of Fig. 3, the amperometric response at $0.0 \mathrm{~V}$ vs. $\mathrm{Ag} / \mathrm{AgCl}$ was due to the oxidation of $\mathrm{TCh}$ (the hydrolysis product of ATCh) catalyzed by the immobilized AChE. The low oxidation overvoltage to TCh and the higher current at the CoTSPc/CNT/OMIM $\left[\mathrm{BF}_{4}\right] / \mathrm{AChE}$ biosensor was due to the electrocatalytic activity of the CoTSPc complex, the large working surface area and electrical conductivity of the CNT.

Other chronoamperometric experiments were performed with the CoTSPc/CNT/OMIM $\left[\mathrm{BF}_{4}\right] / \mathrm{AChE}$ biosensor to different concentrations of ATCh $\left(0,0.1,1.0\right.$ and $\left.5.0 \mathrm{mmol} \mathrm{L}^{-1}\right)$ into

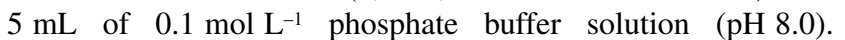
Successive aliquots of the analyte from stock solution of $1 \mathrm{~mol} \mathrm{~L}^{-1}$ were added into electrochemical cell, with polarization of the working electrode at $0.0 \mathrm{~V} v s$. $\mathrm{Ag} / \mathrm{AgCl}$, in order to determine the catalysis rate constant $\left(k_{\text {cat }}\right)$ according to Eq. (4): ${ }^{29}$

$$
\frac{I_{\mathrm{cat}}}{I_{\mathrm{L}}}=\pi^{\frac{1}{2}}\left(k_{\mathrm{cat}} C_{0} t\right)^{\frac{1}{2}},
$$

where $I_{\text {cat }}$ and $I_{\mathrm{L}}$ are the currents in the presence and absence of ATCh, respectively, $k_{\text {cat }}$ the catalysis rate constant, $C_{0}$ the concentration of ATCh, and $t$ the time (in seconds). The time interval used in this experiment was of 0.8 up to $1.7 \mathrm{~s}$. From the slope of a plot $I_{\text {cat }} / I_{\mathrm{L}} v s . t^{1 / 2}$, the kobs value of TCh concentration range $0-5.0 \mathrm{mmol} \mathrm{L}^{-1}$ can be calculate. Figure 4 shows chronoamperograms and experimental data processing for determining the average $k_{\mathrm{obs}}$ value. This figure shows plots constructed from the chronoamperograms (inset of Fig. 4), in the absence and presence of ATCh, and the average $k_{\text {obs }}$ value calculated from the slope $\left(3.67 \times 103 \mathrm{~mol}^{-1} \mathrm{~L} \mathrm{~s}^{-1}\right)$ was higher than, or similar to, the obtained for other types of electrodes employed for TCh detection, ${ }^{14,29}$ indicating that the composite based on CoTSPc/CNT/OMIM[BF $\left.{ }_{4}\right]$ presented excellent electrocatalytic properties in terms of TCh oxidation.

Influence of phosphate buffer $p H$, type of buffer solution and ATCh concentration

The effect of the $\mathrm{pH}$ was first investigated at $\mathrm{pH}$ values of 6.0 ; $6.5 ; 7.0 ; 7.5,8.0$ and 8.5 . There was a considerable increase in 

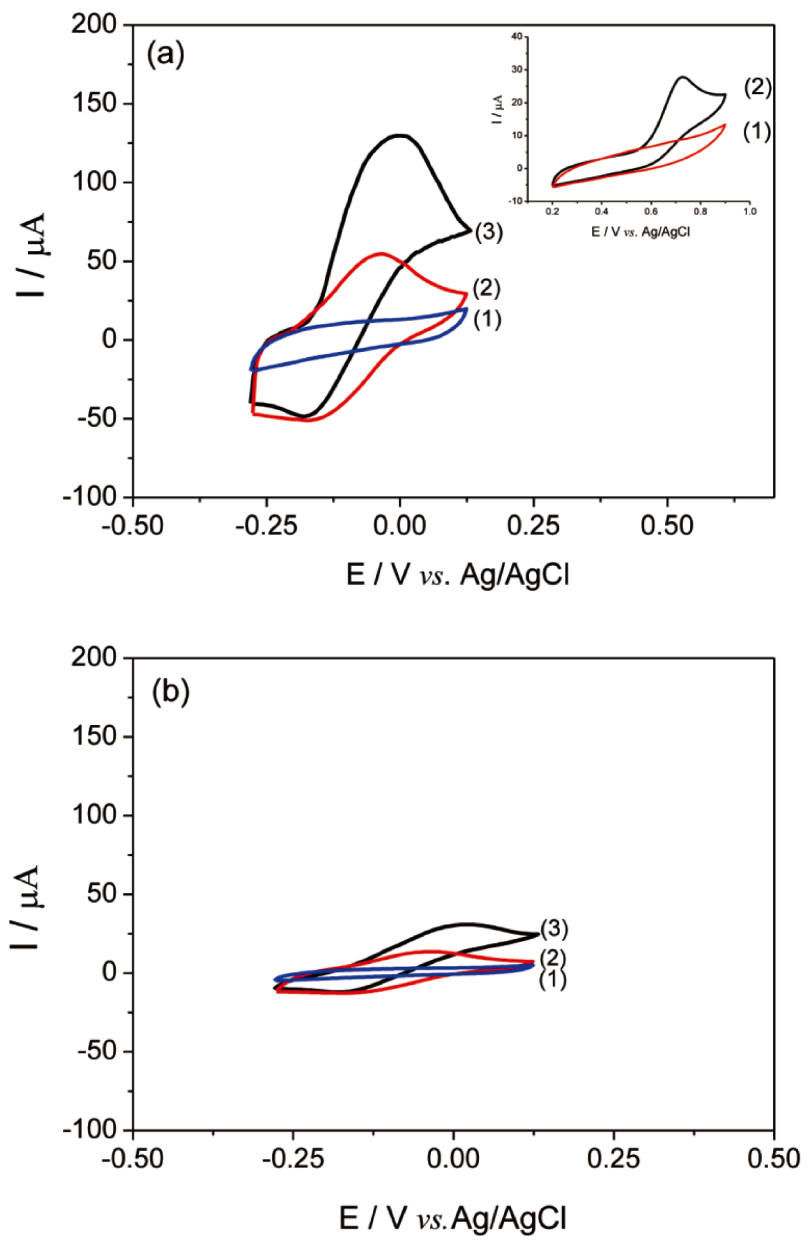

Fig. 2 (a) $\mathrm{CV}$ of the $\mathrm{CNT} / \mathrm{OMIM}\left[\mathrm{BF}_{4}\right]$ paste electrode (curve 1), the $\mathrm{CoTSP} / \mathrm{CNT} / \mathrm{OMIM}\left[\mathrm{BF}_{4}\right]$ paste electrode (curve 2), and the CoTSPc/ $\mathrm{CNT} / \mathrm{OMIM}\left[\mathrm{BF}_{4}\right] / \mathrm{AChE}$ biosensor (curve 3). Inset of Fig. 2(a): CV of unmodified carbon paste electrode in absence (curve 1) and presence (curve 2) of TCh. (b) CV of the CNT/Nujol paste electrode (curve 1), the CoTSPc/CNT/Nujol paste electrode (curve 2), and the CoTSPc/ $\mathrm{CNT} / \mathrm{Nujol} / \mathrm{AChE}$ biosensor (curve 3). All analyses were performed in $\mathrm{pH}$ 8.0 PBS containing $50 \mathrm{mmol} \mathrm{L}^{-1}$ ATCh.

the current between $\mathrm{pH} 6.0$ and 7.0 (1.6 \pm 0.3 up to $43.6 \pm$ $0.1 \mu \mathrm{A})$, after which it remained unchanged at between $\mathrm{pH} 7.0$ and 8.5 (about of $44.0 \pm 0.4 \mu \mathrm{A}$ ). A pH of 8.0 was therefore selected for use in subsequent analyses, since this is close to physiological $\mathrm{pH}$ and provided greater stability of AChE. Four different buffer solutions were tested for their effect on the sensor response, using concentrations of $0.1 \mathrm{~mol} \mathrm{~L}^{-1}$ : Mcllvaine $(25.2 \pm 1.0 \mu \mathrm{A})$, phosphate $(44.9 \pm 0.1 \mu \mathrm{A})$, Tris $(42.5 \pm$ $0.7 \mu \mathrm{A})$, and Hepes $(15.9 \pm 0.4 \mu \mathrm{A})$. The best response was

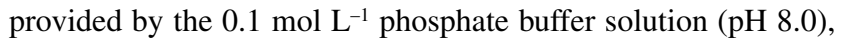
which was therefore used in further experiments.

The dependence of the CoTSPc/CNT/OMIM $\left[\mathrm{BF}_{4}\right] / \mathrm{AChE}$ biosensor response was also investigated by preparing aqueous solutions containing different concentrations of ATCh (between 5.0 and $60.0 \mathrm{mmol} \mathrm{L}^{-1}$ ) from a stock solution of $1 \mathrm{~mol} \mathrm{~L}^{-1}$ at phosphate buffer solution under an applied potential of $0.0 \mathrm{~V} v s$. $\mathrm{Ag} / \mathrm{AgCl}$. In this experiment, the addition of different aliquots of ATCh in electrochemical cell was realized. The current showed an increase at between 5.0 and $50.0 \mathrm{mmol} \mathrm{L}^{-1}$, followed by a decrease (Fig. S2a, Supporting Information). This could have been due to the attainment of equilibrium in the rate at

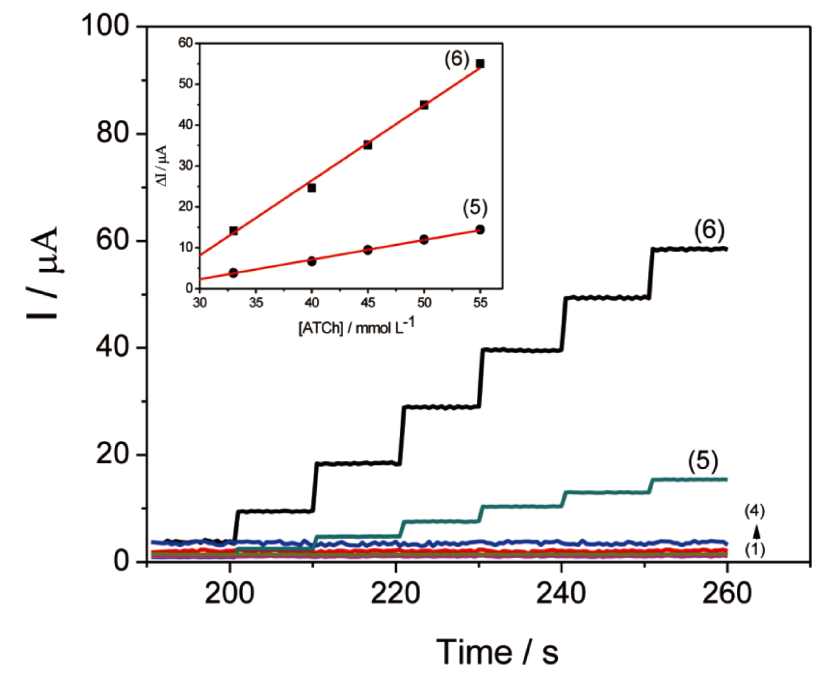

Fig. 3 Amperograms response to CNT/Nujol oil (curve 1), CNT/ OMIM[BF 4 (curve 2), CoTSPc/CNT/Nujol oil (curve 3), CoTSPc/ $\mathrm{CNT} / \mathrm{OMIM}\left[\mathrm{BF}_{4}\right]$ (curve 4), CoTSPc/CNT/Nujol oil/AChE (curve 5), and CoTSPc/CNT/OMIM[BF $\left.\mathrm{BF}_{4}\right] / \mathrm{AChE}$ (curve 6) at different concentrations of ATCh $\left(33.0,38.0,45.0,50.0,55\right.$ and $\left.60.0 \mathrm{mmol} \mathrm{L}^{-1}\right)$ for aliquots of 83.0, 95.0, 113.0, 125.0, 138.0 and $150.0 \mu \mathrm{L}$ of ATCh at electrochemical cell from stock solution of $2.0 \mathrm{~mol} \mathrm{~L}^{-1}$. All analyses were performed in $\mathrm{pH} 8.0 \mathrm{PBS}\left(E_{\text {appl. }}=0.0 \mathrm{~V}\right)$. Inset: The Current intensity response of $\mathrm{AChE}$ based biosensor as a function of the ATCh concentration.

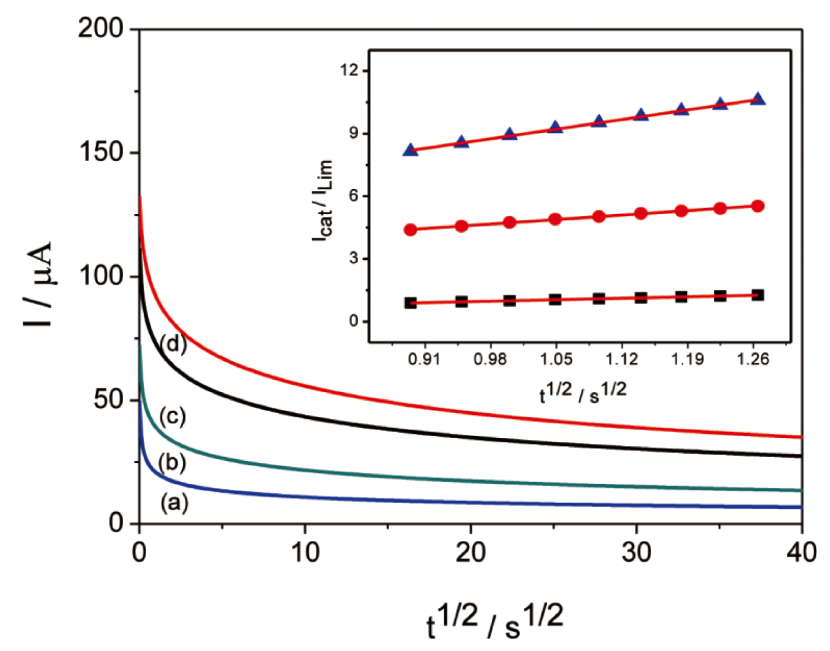

Fig. 4 Chronoamperograms of the CoTSPc/CNT/OMIM $\left[\mathrm{BF}_{4}\right]$ biosensor in (a) absence, and in the presence of ATCh $0.1 \mathrm{mmol} \mathrm{L}^{-1}$ (b), $1.0 \mathrm{mmol} \mathrm{L}^{-1}(\mathrm{c}), 5 \mathrm{mmol} \mathrm{L}-1$ (d). Inset of Fig. 5: plot of $I_{\text {cat }} / I_{\mathrm{Lim}} v s$. $t^{1 / 2}$ derived from chronoamperometric data (Equations: $Y=0.17+$ $\left.1.12 \mathrm{~s}^{1 / 2} ; \quad Y=1.75+3.65 \mathrm{~s}^{1 / 2} ; \quad Y=2.51+6.60 \mathrm{~s}^{1 / 2}\right) . \quad E_{\text {appl }}=0.0 \mathrm{~V}$. Experimental conditions: $0.1 \mathrm{~mol} \mathrm{~L}^{-1}$ phosphate buffer, $\mathrm{pH}$ 8.0).

which the enzyme catalyzed the substrate, so that subsequent increases of the substrate concentration did not increase the catalysis rate. An ATCh concentration of $50.0 \mathrm{mmol} \mathrm{L}^{-1}$ was therefore selected.

Study of the incubation time of the CoTSPc/CNT/OMIM[BF $\left.{ }_{4}\right] /$ AChE biosensor on inhibition of AChE and Pesticides determination

The improvement of pesticide detection can be achieved by increasing the incubation time. ${ }^{12}$ In this work, the current of the 
Table 1 Determination and recovery of OP obtained for different water samples

\begin{tabular}{|c|c|c|c|c|c|c|c|c|}
\hline \multirow{2}{*}{$\begin{array}{l}\text { Samples } \\
\quad N=5\end{array}$} & \multicolumn{2}{|c|}{ [Fenitrothion]/nmol L ${ }^{-1}$} & \multirow{2}{*}{$\begin{array}{c}\text { Samples } \\
N=5\end{array}$} & \multicolumn{2}{|c|}{ [Dichlorvos]/nmol L ${ }^{-1}$} & \multirow{2}{*}{$\begin{array}{c}\text { Samples } \\
N=5\end{array}$} & \multicolumn{2}{|c|}{ [Malathion] } \\
\hline & $\begin{array}{l}\text { Proposed } \\
\text { method }\end{array}$ & $\begin{array}{l}\text { Reference } \\
\text { method }^{46}\end{array}$ & & $\begin{array}{l}\text { Proposed } \\
\text { method }\end{array}$ & $\begin{array}{l}\text { Reference } \\
\text { method }^{46}\end{array}$ & & $\begin{array}{l}\text { Proposed } \\
\text { method }\end{array}$ & $\begin{array}{c}\text { Reference } \\
\text { method }^{46}\end{array}$ \\
\hline $\mathrm{A} 1$ & $0.33( \pm 0.01)$ & $0.32( \pm 0.02)$ & A1 & ND & ND & A1 & ND & ND \\
\hline $\mathrm{A} 2$ & $0.21( \pm 0.02)$ & $0.23( \pm 0.03)$ & $\mathrm{A} 2$ & ND & ND & $\mathrm{A} 2$ & ND & ND \\
\hline B1 & $0.50( \pm 0.05)$ & $0.52( \pm 0.01)$ & B1 & $0.45( \pm 0.03)$ & $0.44( \pm 0.03)$ & B1 & $0.34( \pm 0.02)$ & $0.36( \pm 0.03)$ \\
\hline B2 & $0.60( \pm 0.03)$ & $0.58( \pm 0.04)$ & B2 & $0.40( \pm 0.04)$ & $0.42( \pm 0.02)$ & B2 & $0.38( \pm 0.01)$ & $0.39( \pm 0.02)$ \\
\hline B3 & $0.68( \pm 0.01)$ & $0.69( \pm 0.01)$ & B3 & $0.53( \pm 0.02)$ & $0.54( \pm 0.01)$ & B3 & $0.31( \pm 0.05)$ & $0.31( \pm 0.06)$ \\
\hline $\mathrm{C} 1$ & ND & ND & $\mathrm{C} 1$ & ND & ND & $\mathrm{C} 1$ & ND & ND \\
\hline $\mathrm{C} 2$ & ND & ND & $\mathrm{C} 2$ & ND & ND & $\mathrm{C} 2$ & ND & ND \\
\hline
\end{tabular}

A1. River water 1, A2. River water 2, B1. Underground water 1, B2. Underground water 1, B3. Underground water 1, C1. Tap water 1, C2. Tap water 1 .

CoTSPc/CNT/OMIM[BF 4 / $/ \mathrm{AChE}$ biosensor decreased substantially with increased incubation time (between 2 and $6 \mathrm{~min}$ ) in the OP pesticides solution. Figure S2b (Supporting Information) show that when the incubation time was longer than 6 min (inhibition of about 99\%); the curve tended towards a stable value, indicating the saturation of binding with the active target groups in the enzyme. Thus, an optimum incubation time of 6 min was selected.

The inhibitory effects of the OP pesticides (fenitrothion, dichlorvos, and malathion) on the response of the CoTSPc/ $\mathrm{CNT} / \mathrm{OMIM}\left[\mathrm{BF}_{4}\right] / \mathrm{AChE}$ biosensor were investigated using $50 \mathrm{mmol} \mathrm{L}^{-1}$ ATCh as the substrate in $0.1 \mathrm{~mol} \mathrm{~L}^{-1}$ phosphate buffer solution, $\mathrm{pH}$ 8.0. As shown in Fig. S2c (Supporting Information), when the biosensor was incubated in a known concentration of pesticide standard solution (in this case the fenitrothion) for $6 \mathrm{~min}$, the current decreased drastically (curve 1) compared to incubation without any inhibitor (curve 2). Exposure to $1 \mathrm{nmol} \mathrm{L}^{-1}$ pesticide resulted in a $99 \%$ decrease in the peak current.

The inhibitions caused by the pesticides showed linear relationships in different concentration ranges: $1-1000 \mathrm{pmol} \mathrm{L}^{-1}$ fenitrothion $\left(Y=4.380( \pm 0.131)+9.950( \pm 0.022) \times 10^{10} X, r=\right.$ $0.997, \quad n=11) ; \quad 2-8000 \mathrm{pmol} \mathrm{L}^{-1} \quad$ dichlorvos $\quad(Y=4.362$ $\left.( \pm 0.387)+1.192 \quad( \pm 0.008) \times 10^{10} X, \quad r=0.998, \quad n=7\right) ; \quad$ and $8-5000 \mathrm{pmol} \mathrm{L}^{-1}$ malathion $(Y=12.062 \quad( \pm 0.142)+1.76$ $\left.( \pm 0.043) \times 10^{10} \mathrm{X}, r=0.998, n=8\right)$. The limits of detection were $0.4,0.2$, and $0.7 \mathrm{pmol} \mathrm{L} \mathrm{L}^{-1}$ for fenitrothion, dichlorvos, and malathion, respectively. These limits were calculated using $3 \times \mathrm{SD}_{\mathrm{b}} /$ slope ratio, where $\mathrm{SD}_{\mathrm{b}}$ is the standard deviation calculated from the ten background current values. The detection limits and linear ranges obtained in this work were similar to, or better than, many reported in the literature using other sensors. ${ }^{10,12,30-43}$ This can be attributed to the efficiency of electron transfer between the CoTSPc/CNT/OMIM[BF $\left.{ }_{4}\right] / \mathrm{AChE}$ biosensor and $\mathrm{TCh}$, due to the catalytic effect of the CoTSPc/CNT/OMIM[BF 4 composite. In addition, the reaction occurring at the CoTSPc/ $\mathrm{CNT} / \mathrm{OMIM}\left[\mathrm{BF}_{4}\right] / \mathrm{AChE}$ biosensor very quickly reached a dynamic equilibrium after each addition of the analyte, with a response time of less than $1 \mathrm{~s}$ for the signal to reach $100 \%$. Since the technique showed a combination of high sensitivity, low detection limits, and fast response times, the CoTSPc/CNT/ $\mathrm{OMIM}\left[\mathrm{BF}_{4}\right] / \mathrm{AChE}$ biosensor may have potential applications in electrochemical detectors for the determination of OP pesticides using HPLC and capillary electrophoresis systems.

Reactivation, repeatability, and stability of the biosensor

Another interesting characteristic of the AChE biosensor was that the inhibition induced by the pesticides could be reversed. It has been reported that $98 \%$ of the enzymatic activity can be restored within $15 \mathrm{~min}$ of incubation of the inhibited biosensor in a 2-PAM solution. ${ }^{44,45}$ It is possible that many pesticides could cause this type of reversible inhibition. Here, the repeatability and stability of the CoTSPc/CNT/OMIM[BF 4 / $\mathrm{AChE}$ biosensor was evaluated by performing successive amperometric measurements in $0.1 \mathrm{~mol} \mathrm{~L}^{-1}$ phosphate buffer solution ( $\mathrm{pH} 8.0)$. No change was observed in the amperometric response of the biosensor after 100 determinations, with relative standard deviation (RSD) of $3.5 \%$. Additionally, RSD of $4.5 \%$ was obtained for a series of 10 biosensors prepared in the same manner and tested in $0.1 \mathrm{~mol} \mathrm{~L}^{-1}$ phosphate buffer ( $\mathrm{pH} 8.0$ ) containing $1 \mathrm{nmol} \mathrm{L}^{-1}$ of the pesticides. These results indicated that the CoTSPc/CNT/OMIM[BF $\left.{ }_{4}\right] / \mathrm{AChE}$ biosensor had good stability and repeatability, due to the ability of the CoTSPc/ $\mathrm{CNT} / \mathrm{OMIM}\left[\mathrm{BF}_{4}\right]$ material to increase the rate of electron transfer between $\mathrm{AChE}$ and $\mathrm{TCh}$ in a stable and reproducible way.

\section{Application of the sensor in water samples}

The proposed sensor was employed for the determination of pesticides in river, underground, and tap water samples. The concentrations of pesticides in the samples (using five replicates) were measured using the proposed technique and a reference method for water samples (Table 1). A comparison of the two methods using the paired Student's $t$-test showed that there were no statistically significant differences (at the $95 \%$ confidence level). The concentrations of pesticides were determined using calibration curves generated using external standards. The results showed that, for the samples evaluated, the new biosensor was not influenced by any matrix interferences. The recovery of the spiked samples ranged between 97 and 102\%, indicating that the proposed biosensor is effective, and can be applied for OP determination in real samples. These findings demonstrated that this biosensor is a feasible alternative for pesticide determination, offering a combination of sensitivity, robustness, stability, precision, and speed.

\section{Conclusions}

The CoTSPc/CNT/OMIM[BF $4 /$ AChE biosensor developed here presents excellent electrochemical properties in terms of TCh oxidation, enabling the ssable and sensitive detection of TCh at low oxidation potential $(0.0 \mathrm{~V} v s$. $\mathrm{Ag} / \mathrm{AgCl})$. TCh oxidation on the CoTSPc/CNT/OMIM[BF $\left.{ }_{4}\right] / \mathrm{AChE}$ biosensor showed a larger 
current, compared to a Nujol oil/CoTSPc/CNT/AChE biosensor. This could be explained by the electrocatalytic activity of the CoTSPc complex, the high surface area and high electrical conductivity of the CNT, and the ability of the OMIM[BF $\left.{ }_{4}\right]$ ionic liquid to accelerate the electron-transfer kinetics of TCh oxidation, due to the electrostatic interaction between negatively charged TCh and the imidazolium cation. This amperometric biosensor was successfully developed for a highly sensitive determination of OP pesticides, and provided very low detection limits combined with high sensitivity. The work described here illustrates a simple and novel approach to the development of improved amperometric enzyme-based sensors for pesticide determination.

\section{Acknowledgements}

The authors are grateful to Conselho Nacional de Desenvolvimento Científico e Tecnológico (CNPq), INCTBio, Fundação de Amparo à Pesquisa do Estado do Maranhão (FAPEMA), and Rede Mineira de Química for financial support.

\section{Supporting Information}

Supplementary data shows: Fig. S1 - Reaction scheme for the amperometric detection of AChE inhibition. Fig. S2 - (a) Effect of ATCh concentration and (b) pesticide incubation time on the response of the biosensor. (c) Amperograms obtained using the biosensor. This material is available free of charge on the Web at http://www.jsac.or.jp/analsci/.

\section{References}

1. Directive 2000/60/EC of the European Parliament and of the Council, Official Journal L, 2000, 327, 1.

2. C. Bolognesi, Mutat. Res., 2003, 543, 251.

3. H. Schulze, S. Vorlová, F. Villatte, T. Bachmann, and R. Schmid, Biosens. Bioelectron., 2003, 18, 201.

4. P. C. Pandey, S. Upadhyay, H. C. Pathak, C. M. D. Pandy, and I. Tiwari, Sens. Actuators, B, 2000, 109, 62.

5. A. Sassolas, B. Prieto-Simón, and M. J. L. Marty, Am. J. Anal. Chem., 2012, 3, 210.

6. F. Arduini, A. Cassisi, A. Amine, F. Ricci, D. Moscone, and G. Palleschi, J. Electroanal. Chem., 2009, 626, 66.

7. L. G. Zamfir, L. Rotariu, and C. Bala, Biosens. Bioelectron., 2013, 46, 61 .

8. J. Yan, H. Guan, J. Yu, and D. Chi, Pestic. Biochem. Physiol., 2013, 105, 197.

9. H. Parham and N. Rahbar, J. Hazard. Mater., 2010, 177, 1077.

10. D. Du, M. Wang, J. Cai, Y. Qin, and A. Zhang, Sens. Actuators, B, 2010, 143, 524.

11. B. Bucur, D. Fournier, A. Danet, and J. L. Marty, Anal. Chim. Acta, 2006, 562, 115.

12. X. Sun and X. Wang, Biosens. Bioelectron., 2010, 25, 2611.

13. X. H. Li, Z. Xie, H. Min, C. Li, M. Liu, Y. Xian, and L. Jin, Electroanalysis, 2006, 18, 2163.

14. F. Arduini, A. Cassisi, A. Amine, F. Ricci, D. Moscone, and G. Palleschi, J. Electroanal. Chem., 2009, 626, 66.

15. L. G. Zamfirb, L. Rotariua, and C. Bala, Biosens. Bioelectron., 2011, 26, 3692.

16. J. Zhang, A. Luo, P. Liu, S. Wei, and G. Wang, Anal. Sci., 2009, 25, 511.
17. J. Dou, F. Fan, A. Ding, L. Cheng, R. Sekar, H. Wang, and S. Li, J. Environ. Sci. (Beijng, China), 2012, 24, 956.

18. X. Meng, J. Wei, X. Ren, J. Ren, and F. Tang, Biosens. Bioelectron., 2013, 15, 402.

19. G. A. Rivas, M. D. Rubianes, M. C. Rodríguez, N. F. Ferreyra, G. L. Luque, M. L. Pedano, S. A. Miscoria, and C. Parrado, Talanta, 2007, 74, 291.

20. S. Zein El, Abedin, K. S. Ryder, O. Höfft, and H. K. Farag, Int. J. Electrochem., 2012, 2012, 1.

21. R. C. S. Luz, A. B. Moreira, F. S. Damos, A. A. Tanaka, and L. T. Kubota, J. Pharm. Biomed. Anal., 2006, 42, 184.

22. J. Zagal, C. Fierro, and R. Rozas, J. Electroanal. Chem., 1981, 119, 403.

23. J. H. Weber and D. H. Busch, Inorg. Chem., 1965, 4, 469.

24. A. Gahlaut, A. Gothwal, A. K. Chhillar, and V. Hooda, Open J. Appl. Biosens., 2012, $1,1$.

25. J. Lee, E. J. Park, J. Choi, J. Hong, and S. E. Shim, Synth. Met., 2010, 160, 566.

26. C. Dhand, S. K. Arya, S. P. Singh, B. P. Singh, M. Datta, and B. D. Malhotra, Carbon, 2008, 46, 1727.

27. D. Verma, R. Dasha, K. S. Katti, D. S. Schulz, and A. N. Caruso, Spectrochim. Acta, Part A, 2008, 70, 1180.

28. A. P. F. Turner, I. Karube, and G. S. Wilson, "Biosensors: Fundamentals and Applications", 1988, Oxford University Press, Oxford.

29. L. Rotariu, L. G. Zamfir, and C. Bala, Sens. Actuators, B, 2010, 150, 73 .

30. N. Chauhan, J. Narang, and C. S. Pundir, Biosens. Bioelectron., 2011, 29, 82.

31. L. Jin, Y. Wei, Y. Li, Y. Qu, F. Xiao, and G. Shi, Anal. Chim. Acta, 2009, 643, 13.

32. A. C. Ion, I. Ion, A. Culetu, D. Gherase, C. A. Moldovan, R. Iosub, and A. Dinescu, Mater. Sci. Eng., C, 2010, 30, 817.

33. L. Stanciu, R. Sinhaa, M. Ganesanab, and S. Andreescu, Anal. Chim. Acta, 2010, 661, 195.

34. J. L. Marty, H. Zejli, J. L. H. H. Cisneros, I. NaranjoRodriguez, B. Liu, and K. R. Temsamani, Talanta, 2008 , 77, 217.

35. N. Chauhan, J. Narang, and C. S. Pundir, Int. J. Biol. Macromol., 2011, 49, 923.

36. N. Chauhan and C. S. Pundir, Electrochim. Acta, 2012, 67, 79 .

37. N. Chauhan and C. S. Pundir, Anal. Chim. Acta, 2011, 701, 66.

38. L. Yanrong, G. Zhiyong, L. Yanfen, L. Qian, B. Jianchun, D. Zhihui, and H. Min, Sci. China: Chem., 2010, 53, 820.

39. S. Upadhyay, G. R. Rao, M. K. Sharma, B. K. Bhattacharya, V. K. Rao, and R. Vijayaraghavan, Biosens. Bioelectron., 2009, 25, 832 .

40. K. Wang, H. N. Li, J. Wu, C. Ju, J. J. Yan, Q. Liu, and B. Qiu, Analyst, 2011, 136, 3349.

41. P. Norouzi, M. Pirali-Hamedani, M. R. Ganjali, and F. A. Faridbod, Int. J. Electrochem. Sci., 2010, 5, 1434.

42. Y. Song, M. Zhang, L. Wang, L. Wan, X. Xiao, S. Ye, and J. Wang, Electrochim. Acta, 2011, 56, 7267.

43. T. Godjevargova, I. Marinov, Y. Ivanov, and K. Gabrovska, J. Mol. Catal. B: Enzym., 2010, 62, 67.

44. F. Arduini, F. Ricci, C. S. Tuta, D. Moscone, A. Amine, and G. Palleschi, Anal. Chim. Acta, 2006, 58, 155.

45. K. Anitha, S. V. Mohan, and S. J. Reddy, Biosens. Bioelectron., 2004, 20, 848.

46. C. Gonçalves and M. F. Alpendurada, J. Chromatogr. A, 2002, 968, 177. 